\title{
Méliès' A Trip to the Moon in Colour
}

\author{
By Jan Uhde
}

Spring 2012 Issue of KINEMA

\section{GEORGES MÉLIÈS: A TRIP TO THE MOON IN COLOUR}

Without doubt, the DVD medium can now be considered as a kind of video establishment. Even the more recent Blu-ray disc (BD) is becoming a familiar sight in home theatres. Thousands of new movie titles, many in parallel editions are flooding the video stores, while the prices are sinking, pushed down by generous sales. Moreover, the restoration of old films, shattering cultural, geographical and temporal boundaries are becoming more frequent and more sophisticated, taking advantage of advanced restoration technologies.

There is, however, always space for a new discovery and genuine surprise. One such event may be the uncovering and subsequent restoration of the hand-coloured version of the fourteen-minute 1902 Trip to the Moon (Le voyage dans la lune) by the first magician of cinema Georges Méliès - the founding father of both the fiction film and the science-fiction movie genre. The hand-coloured version of his A Trip to the Moon, a well-known classic inspired by the sci-fi novel of Jules Verne, was made with the help of an early colouring technique involving teams of women painting individual frames with tiny brushes using aniline dyes.

Considered lost by film historians and old-celluloid hunters alike, an original print unexpectedly surfaced in the Filmoteca de Catalunya in Barcelona in 1993. But it was in a very poor shape. According to Serge Bromberg of Lobster Films, the celluloid "had deteriorated into a solid decomposed mass and was damaged beyond all likely repair." The immense historical value of the find however persuaded Bromberg and his collaborator Eric Lange to attempt the impossible.

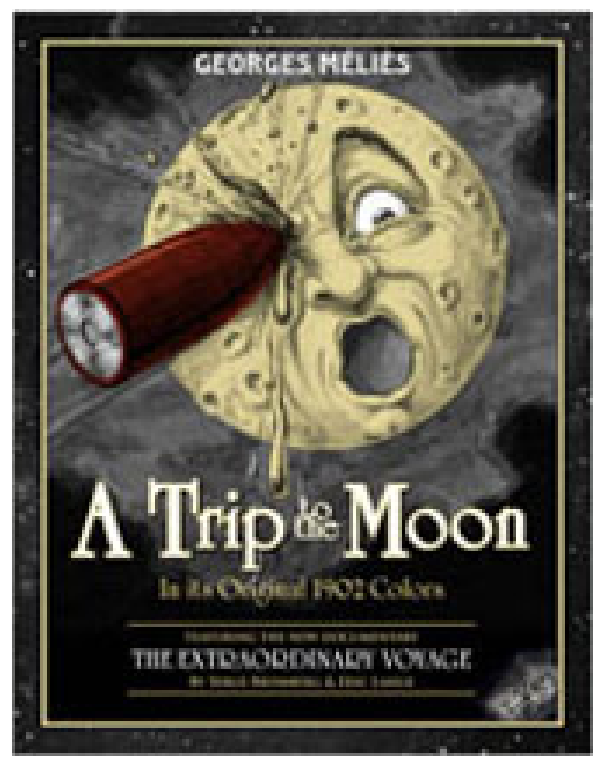

Figure 1: A Trip to the Moon DVD set restored (Limited edition, Steelbox). Prod.: Flicker Alley, 2012 (BR Region A) \$39.99. Other options available. I

The restoration of the film eventually became a collaborative effort between Lobster Films (Paris) and two non-profit establishments, Groupama Gan Foundation for Cinema and Technicolor Foundation for Cinema 
Heritage. The painstaking restoration which necessitated the most sophisticated digital technologies as well as non-orthodox chemical treatment stretched up to ten years, but the result was nothing short of spectacular. The restored film was first publicly presented at the 2011 Festival de Cannes, most appropriately commemorating the 150th anniversary of Méliès' birth.

At the end of 2011, a video release of the restored movie was announced for the end of March 2012. A Trip to the Moon displaying its original 1902 colours and a soundtrack by the Parisian electronic duo AIR (Nicolas Godin and JB Dunckel), accompanied by Lobster Films' 78-minute documentary The Extraordinary Voyage, will be first released in a limited two-disc Blu-ray plus DVD SteelBook Edition (pre-release price is US \$29.96). This remarkable restoration won a 2011 Film Heritage Award from the US National Society of Film Critics.

Both the DVD and Blu-ray discs will include two other shorts by Méliès thematically tied to the Moon: The Eclipse (1907, drawn from an original negative) and The Astronomer's Dream (1898), from the Lobster Films Collection. On the Blu-ray, these films are recorded in high definition.

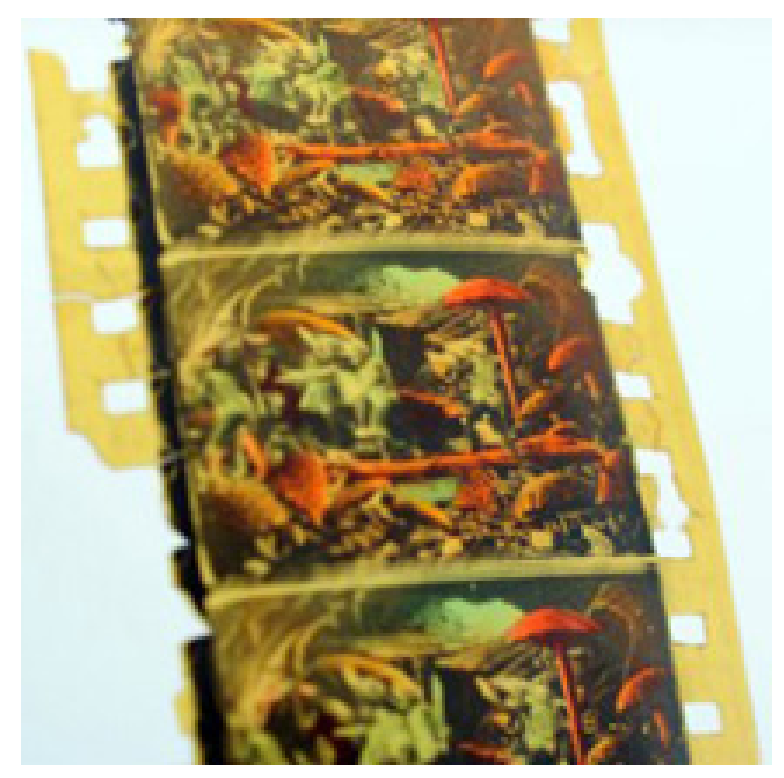

Figure 2: A Trip to the Moon film damage sample

\section{Author Information}

Jan UHDE is Professor Emer. (Film Studies) at the University of Waterloo, Ontario, Canada. Born in Brno, Czech Republic. Graduated (MA) from the Faculty of Arts, Masaryk University, Brno; PhD received at the University of Waterloo, Ontario, Canada. He taught at the University of Waterloo (1970-2012) where he founded a General and Honours BA program in Film Studies at the Department of Fine Arts.

Publications: Latent Images: Film in Singapore Second edition, with Yvonne Ng Uhde (Ridge Books, National University Press of Singapore, 2010); Latent Images: Film in Singapore, with Yvonne Ng Uhde (Oxford University Press, 2000); Latent Images: Film in Singapore CD-ROM (2003, co-author); Vision and Persistence: Twenty Years of the Ontario Film Institute (University of Waterloo Press, 1990) and Ontario Film Institute Programming Activities Index 1969-1989 (Toronto: Ontario Science Centre, 1990). He co-edited the Place in Space: Human Culture in Landscape (Proceedings from the Second International Conference of the Working Group "Culture and Landscape" of the International Association of Landscape Ecology, Pudoc Scientific Publishers, Wageningen, Holland, 1993). Jan Uhde has published articles and reviews in several countries (including Canada, USA, Germany, Italy), participated in international juries at film festivals and 
presented papers at international conferences in North America and Europe. In 1998/99, he was a visiting researcher at the School for Film and Media Studies, Ngee Ann Polytechnic, Singapore.

His professional and research interests focus on Singapore cinema; the identification and distancing mechanisms of the film viewer; the non-authored modifications and manipulation of films; and specific aspects of film history, including the Central European cinema.

He founded KINEMA in 1993. 